\title{
AVALIAÇÃO E APROVEITAMENTO DO RESÍDUO DE ÓLEO VEGETAL COLETADO NO RU/UFTM PARA A PRODUÇÃO DE BIODIESEL
}

\author{
V. V. COUTINHO, T. M. de JESUS, D. M. FERNANDES, G. R. P. MALPASS e \\ P.P. SILVA
}

Universidade Federal do Triângulo Mineiro, Departamento de Engenharia Química. E-mail para contato: priscila@icte.uftm.edu.br

\begin{abstract}
RESUMO - O descarte inadequado do óleo residual de fritura pode causar grandes consequências ambientais como contaminação do solo e água. Desta forma, a produção de biodiesel a partir do óleo vegetal usado apresenta-se como uma alternativa vantajosa para o reuso deste produto. Assim o objetivo deste trabalho foi avaliar as propriedades físico-químicas do óleo residual gerado no Restaurante Universitário - Universidade Federal do Triângulo Mineiro a fim de avaliar seu potencial para geração de biodiesel que posteriormente poderá ser utilizado no maquinário da UFTM. Foi realizado o monitoramento do óleo residual dos meses de setembro à dezembro de 2014. A reação utilizada para a produção de biodiesel foi a de transesterificação metílica alcalina com um rendimento de $93 \%$ de conversão $(\mathrm{m} / \mathrm{m})$. Além disso, foram avaliadas também algumas propriedades do biodiesel produzido com o intuito de analisar a qualidade do produto. Os resultados mostraram que o índice de acidez foi igual a $0,4622 \mathrm{mg} \mathrm{KOH} / \mathrm{g}$ óleo, densidade de $879,2 \mathrm{Kg} / \mathrm{m}^{3}$ e teor de água abaixo de $1 \%$. Todos os resultados mostraram a viabilidade para a produção do biodiesel com baixo custo operacional.
\end{abstract}

\section{INTRODUÇÃO}

A demanda por novas fontes de energia devido a eminente escassez dos recursos fósseis tem impulsionado a necessidade de se buscar por novas estratégias de reuso de materiais potencialmente geradores de energia. Dentre as possibilidades, destaca-se o reuso do óleo de fritura com a finalidade de se produzir biodiesel que já está sendo utilizado em substituição ao óleo diesel por apresentar características bastante similares. A utilização do biodiesel destacase também por não ser tóxico e por apresentar uma melhor qualidade de emissão de gases poluentes durante a combustão (Lôbo, I.P; Ferreira, S.L.C (2009)). Além disso, a possibilidade da utilização de um combustível de origem residual é muito atrativa tendo em vista o aspecto ambiental, devido principalmente por apresentar uma redução na dependência do petróleo.

O biodiesel é produzido a partir de um processo de transesterificação de triglicerídeos em moléculas de ésteres de ácidos graxos. Em sua maioria é produzido por catálise básica em meio homogêneo utilizando-se vários tipos de óleos vegetais in natura (Canakci, 2007) Contudo, a produção de biodiesel a partir do óleo vegetal residual apresenta-se como uma 
alternativa muito mais vantajosa em comparação ao simples descarte deste material no meio ambiente, devido a produção de um composto de maior valor agregado. Entretanto, parâmetros como índices de iodo, saponificação, acidez e umidade do óleo residual devem ser previamente avaliados a fim de se analisar o real potencial para a produção de biodiesel. Isso porque, o uso de temperaturas muito elevadas, o contato com o alimento e o reuso sistemático deste óleo pode vir a comprometer o rendimento do biodiesel tornando assim o processo inviável economicamente. Além disso, para que o biodiesel comercial seja considerado de boa qualidade é necessária também a avaliação de parâmetros físico-químicos como umidade, densidade e acidez, a fim de se obter uma maior eficiência na queima e consequente redução na deposição de compostos indesejáveis no motor.

Neste contexto, as Instituições de Ensino Superior (IES) apresentam um importante papel no que diz respeito à gestão dos seus resíduos produzidos e o controle dos efeitos do mesmo no meio ambiente. Desta forma, a busca por alternativas ao uso do óleo residual gerado na IES torna-se um passo imprescindível ao uso consciente dos recursos e um estimulo a educação ambiental de todos. O objetivo deste trabalho foi avaliar as propriedades físicoquímicas do óleo residual produzido no Restaurante Universitário- campus ICTE da Universidade Federal do Triângulo Mineiro (UFTM) com o intuito de avaliar seu potencial para a produção de biodiesel. Foram avaliadas também as propriedades físico-químicas no biodiesel gerado a partir da reação de transesterificação metílica alcalina a fim de analisar seu rendimento e o custo do processo.

\section{MATERIAIS E MÉTODOS}

\section{1. Óleo residual}

A coleta do óleo residual foi realizada no Restaurante Universitário - campus ICTE da Universidade Federal do Triângulo Mineiro (UFTM) entre os meses de setembro a dezembro de 2014 em um total de 4 amostras. Antes de passar pelo processo de avaliação físico-química as amostras foram devidamente identificadas e filtradas em um sistema a vácuo com pano de algodão. O óleo residual foi então homogeneizado e armazenado em um frasco âmbar.

\subsection{Análises físico-químicas}

Todas as análises físico-químicas foram determinadas pela metodologia oficial, descrita pelo Instituto Adolfo Lutz (Instituto Adolfo Lutz, 2008) e realizadas em triplicatas.

\subsection{1. Índice de acidez}

Em um erlenmeyer de $125 \mathrm{~mL}$ colocou-se $2 \mathrm{~g}$ da amostra do óleo residual. Adicionouse $30 \mathrm{~mL}$ de solução: éter etílico e álcool etílico 1:1 (v/v). Agitou-se até a completa diluição do óleo. Foram adicionados ao sistema 3 gotas do indicador fenolftaleína. Procedeu-se a titulação com solução de $\mathrm{KOH}(0,1 \mathrm{~N})$ até o surgimento da coloração rósea, estável por 30 segundos. 


\subsection{2. Índice de peróxido}

Em um erlenmeyer de $125 \mathrm{~mL}$ foram colocados $1 \mathrm{~g}$ da amostra do óleo residual. Em seguida, adicionou-se $6 \mathrm{~mL}$ de solução: ácido acético e clorofórmio $3: 2(\mathrm{v} / \mathrm{v})$ e $0,1 \mathrm{~mL}$ de solução saturada de iodeto de potássio. Agitou-se por cerca de 2 minutos. Em seguida, adicionou-se $40 \mathrm{~mL}$ de água destilada e $0,1 \mathrm{~mL}$ de solução de amido a $1 \%$. Procedeu-se à titulação com solução de tiossulfato de sódio a $0,01 \mathrm{M}$ até a mistura ficar transparente.

\subsection{3. Índice de saponificação}

Em um balão de fundo redondo, colocou-se $5 \mathrm{~g}$ do óleo residual. Adicionou-se $50 \mathrm{~mL}$ de uma solução alcoólica de KOH. Preparou-se um branco e realizou-se o procedimento analítico simultaneamente com a amostra. Conectou-se o balão ao condensador e deixou-se ferver suavemente até a completa saponificação da amostra. Após o resfriamento do frasco, lavou-se a parte interna do condensador com um pouco de água e adicionou-se 3 gotas do indicador. Titulou-se com uma solução de ácido clorídrico 0,5 M.

\subsubsection{Umidade}

Aqueceu-se o cadinho por 1 hora em estufa a $105^{\circ} \mathrm{C}$. Em seguida, colocou-se no dessecador com sílica para o resfriamento total do cadinho. Mediu-se a massa do cadinho e aproximadamente $3,00 \mathrm{~g}$ da amostra. A amostra foi colocada em estufa a $105^{\circ} \mathrm{C}$. Após 1 hora colocou-se no dessecador até o resfriamento à temperatura ambiente. Realizou-se a pesagem. Repetiu-se o procedimento até massa constante.

\subsubsection{Densidade}

Para a determinação da densidade foi utilizada a técnica da picnometria. Primeiramente, mediu-se a massa do picnômetro $(50 \mathrm{~mL})$ limpo e vazio. Completou-se o picnômetro com água para a calibração do mesmo. Mediu o volume do picnômetro de acordo com a temperatura de análise $\left(20^{\circ} \mathrm{C}\right)$. Em seguida, adicionou-se amostra tomando cuidado para evitar a formação de bolhas. Secou-se completamente o picnômetro e realizou-se a pesagem. De posse da massa e do volume do picnômetro, foi possível obter a densidade na temperatura estabelecida.

\subsection{Reação de transesterificação}

O biodiesel foi obtido pela reação de transesterificação. Nesse processo, $20 \mathrm{~g}$ de metanol $\left(\mathrm{CH}_{3} \mathrm{OH}\right)$ foram misturados à $1 \mathrm{~g}$ de hidróxido de potássio $(\mathrm{KOH})$ até sua completa dissolução. Em seguida, essa mistura foi transferida para um erlenmeyer contendo $100 \mathrm{~g}$ de óleo residual. Essa mistura foi agitada durante 1 hora em agitador magnético. Em seguida, o produto reacional foi transferido para um funil de decantação, onde após aproximadamente 20 minutos, iniciou-se a separação das fases, sendo a fase superior a fase rica em ésteres (biodiesel) e fase inferior a glicerina. Após 24 horas de decantação essas fases foram separadas e o biodiesel seguiu para o processo de lavagem. Foram realizadas 6 lavagens de 50 $\mathrm{mL}$ com água destilada a $85^{\circ}$ afim de retirar o excesso de base residual da reação. Feitas as 
lavagens, o biodiesel foi secado em rotaevaporador durante 1 hora a uma temperatura de $90^{\circ}$ para retirada de álcool e água.

\section{RESULTADOS E DISCUSSÕES}

\subsection{Análise físico-química do óleo residual}

Os testes de índice de acidez, índice de peróxido, índice de saponificação, umidade e densidade das quatro amostras de óleo residual, obtidas respectivamente nos meses de setembro, outubro, novembro e dezembro de 2014 do Restaurante Universitário ICTE/UFTM são descritos na Tabela 1 a seguir:

Tabela 1: Propriedades físico-químicas do óleo residual

\begin{tabular}{cccccc}
\hline & $\begin{array}{c}\text { Índice de } \\
\text { acidez } \\
(\mathrm{mg} \mathrm{KOH} / \mathrm{g} \text { óleo })\end{array}$ & $\begin{array}{c}\text { Índice de } \\
\text { peróxido } \\
(\mathrm{meq} / \mathrm{Kg} \text { óleo })\end{array}$ & $\begin{array}{c}\text { Índice de } \\
\text { saponificação } \\
(\mathrm{mg} \mathrm{KOH} / \mathrm{g} \text { óleo })\end{array}$ & $\begin{array}{c}\text { Umidade } \\
(\%)\end{array}$ & $\begin{array}{c}\text { Densidade } \\
\left(\mathrm{Kg} / \mathrm{m}^{3}\right)\end{array}$ \\
\hline Amostra 1 & 0,7300 & 7,3823 & 190,21 & 1,7549 & 920,11 \\
\hline Amostra 2 & 0,7450 & 7,7898 & 190,87 & 1,8827 & 920,40 \\
\hline Amostra 3 & 0,7478 & 8,8677 & 196,67 & 2,7218 & 922,89 \\
\hline Amostra 4 & 0,7233 & 6,8324 & 189,49 & 1,4739 & 920,85 \\
\hline
\end{tabular}

O índice de acidez mede a quantidade de ácido graxo livre na amostra, o que é um parâmetro indicativo do estado de conservação do óleo. Nota-se que todas as amostras apresentam índices de acidez relativamente baixos para um óleo residual, sendo que a amostra 4 foi a que apresentou o menor índice de acidez. O percentual de umidade obtido em todas as amostras foi também relativamente baixo. De acordoo com Agarwal e colaboradores (2012) altos índices de acidez e água podem dificultar ou mesmo inviabilizar o processo de produção de biodiesel via catálise homogênea em meio alcalino favorecendo a reação paralela à reação de transesterificação que é a saponificação.

Os peróxidos são os principais produtos iniciais da autoxidação e sua avaliação é efetuada pela determinação do índice de peróxidos (Jorge, N (2009)). O aquecimento intermitente, sob a ação do oxigênio do ar acelera o mecanismo de deterioração de óleos pela ação da hidrólise e oxidação (Encinar et al. (2005)). Neste trabalho, observa-se que a amostra 3 foi a que apresentou o maior índice de peróxido indicando que nesta amostra, provavelmente o processo de oxidação foi maior, podendo estar relacionado a um pior acondicionamento da amostra.

O índice de saponificáveis de uma matéria prima pode justificar o baixo rendimento na produção de biodiesel obtida pelo óleo residual, em comparação ao óleo vegetal refinado que apresenta índices de saponificação entre 180-200 mg KOH/g óleo. Isso porque, uma amostra de óleo usado que apresenta altos índices de saponificação indica uma maior tendência à 
formação de sabão. Observa-se que as amostras apresentaram valores de índice de saponificação próximos e relativamente baixos indicando que o óleo residual proveniente do RU-UFTM apresenta baixos índices de deterioração, pois, são utilizados uma vez durante a fritura de alimentos. Já os resultados de densidade de todas as amostras são valores compatíveis com os parâmetros previstos pela ANVISA para óleos residuais.

Para a produção de biodiesel optou-se em realizar a reação de transesterificação metílica alcalina, pois de acordo com Costa Neto (2000) um maior rendimento para reações de produção de biodiesel a partir de óleo residual de fritura é obtido com o metanol em meio alcalino, caso a matéria prima obtenha valores de índice de acidez inferiores à $3 \mathrm{mg} \mathrm{KOH} / \mathrm{g}$ de óleo e além disso, é a forma mais comumente empregada comercialmente para a produção de biodiesel. É importante salientar que neste procedimento, foi utilizada a amostra número 4 que apresentou os menores valores de acidez, peróxido e saponificação. Assim, estes dados indicam, um menor estado de deterioração desta amostra. O rendimento $(\mathrm{m} / \mathrm{m})$ obtido de biodiesel foi em torno de $93 \%$.

Os resultados da análise físico-química do biodiesel produzido neste trabalho estão apresentados na Tabela 2 a seguir:

Tabela 2: Propriedades físico-químicas do biodiesel

\begin{tabular}{ccccc}
\hline & $\begin{array}{c}\text { Índice de acidez } \\
\text { (mg KOH/g óleo) }\end{array}$ & $\begin{array}{c}\text { Índice de } \\
\text { peróxido } \\
\text { (meq/Kg óleo })\end{array}$ & $\begin{array}{c}\text { Densidade } \\
\left(\mathrm{Kg} / \mathrm{m}^{3}\right)\end{array}$ & $\begin{array}{c}\text { Umidade } \\
(\%)\end{array}$ \\
\hline Biodiesel & 0,4622 & 0,7582 & 879,2 & 0,7552 \\
\hline
\end{tabular}

A partir da tabela 2 é possível observar que o índice de acidez obtido foi igual a 0,4622 $\mathrm{mg} \mathrm{KOH} / \mathrm{g}$ óleo e, está de acordo com a legislação prevista pela ANP ${ }^{\circ} 45$ que estipula um índice máximo de acidez para o biodiesel menor que $0,50 \mathrm{mg} \mathrm{KOH} / \mathrm{g}$ óleo. Baixos valores de umidade são pré-requisitos necessários para a utilização do biodiesel no motor diesel a fim de evitar o processo de corrosão. Neste trabalho o nível de porcentagem de água obtido no biodiesel ficou abaixo de $1 \%$.

De acordo com Alptekin e Canakc (2008) o biodiesel obtido a partir do óleo de soja refinado deve apresentar densidade igual a $880 \mathrm{Kg} / \mathrm{m}^{3}$ a $15^{\circ} \mathrm{C}$. $\mathrm{O}$ valor de densidade obtido neste trabalho para o biodiesel utilizando óleo de fritura residual foi igual a $877,2 \mathrm{Kg} / \mathrm{m}^{3}$ a $20^{\circ} \mathrm{C}$. É importante salientar que a densidade do biodiesel foi menor do que o obtido pelo óleo residual, o que confirma a formação do biodiesel a partir da reação de transesterificação com o metanol em meio básico pela amostra 4. Além disso, este resultado de densidade é um indicativo de que o óleo residual apresenta-se em estágio inicial de deterioração e que pode ser preferencialmente utilizado para a produção de biodiesel, que apresenta maior valor agregado com baixo custo de produção, ao invés de ser descartado por outros meios. 


\section{CONCLUSÕES}

Os resultados de análise físico-químicos obtidos a partir do óleo de fritura residual do RU/UFTM e, do biodiesel produzido, sugerem que este óleo residual apresenta baixos índices de deterioração o que o qualifica preferencialmente à produção de um biodiesel de boa qualidade por um método de baixo custo. Sendo assim, esta seria uma proposta viável à geração de biodiesel para ser utilizado pela IES a partir do aproveitamento de um subproduto que apresenta alto potencial poluidor.

\section{AGRADECIMENTO}

Os autores agradecem ao CNPQ pela bolsa de IC.

\section{REFERÊNCIAS BIBLIOGRÁFICAS}

AGARWAL, M., CHAUHAN, G., CHAURASIA,S.P., SINGH, K. Study of catalytic behaviour of $\mathrm{KOH}$ as homogeneous and heterogeneous catalyst for biodiesel production. Journal of the Taiwan Institute of Chemical Engineering. V.43, p.89-94, 2012.

ALPTEKIN, E. ; CANAKC, M. Determination of the density and the viscosity of biodiesel-diesel fuel blends. Renewable Energy, v.33, p. 2623-2630, 2008

CANAKCI, M. The potential of restaurant waste lipids as biodiesel feedstocks. Bioresource Technology, V. 98, p. 183-190, 2007.

COSTA NETO, P.R. Produção de biocombustível alternativo ao óleo diesel através da transesterificação de óleo de soja usado em frituras. Química Nova, v.23, n 04, p.531-537, 2000 .

ENCINAR, J.M., GONZÁLEZ, J.F., RODRIGUEZ-REINARES, A. Biodiesel from used frying oil. Variables affecting the yelds and characteristics of the biodiesel. Ind.Eng.Chem.Res. v.44, p.5491-5499, 2005.

INSTITUTO ADOLFO LUTZ. Métodos Fisico-Químicos para análises de alimentos. São Paulo: Instituto Adolfo Lutz, 2008.

JORGE, N. Química e Tecnologia de Óleos Vegetais. Cultura Acadêmica: Universidade Estadual Paulista, 2009.

LÔBO, I.P; FERREIRA, S.L.C. Biodiesel: Parâmetros de Qualidade e Métodos Analíticos. Química Nova, v.32, n 06, p.1596-1608, 2009. 